\title{
UN DOCUMENT DE SANTES CREUS DINS EL FONS «SCALA DEI» DE L'ARXIU HISTORIC NACIONAL: \\ La compra d'unes terres en el terme de Mur (1197)
}

\author{
Josep Trenchs \\ Universidad de Valencia
}

1. INTRODUCCIÓ

Fa uns anys, en estudiar la documentació de la cartoixa de Scala Dei -Priorat-, ens va apareixer entre els fons de pergamí de l'Arxiu Històric Nacional de Madrid, un document pertanyent al monestir de Santes Creus.

Avui, en aquestes breus notes, l'oferim als estudiosos del monestir, ja que, en referir-se a les terres del castell i terme de Mur, dins la Segarra, completa les noticies que ens dóna el «Llibre Blanch" sobre aquest terme.

Jurídicament es una venda amb totes les característiques típiques de les de l'época en que fou escrita. La seva matèria escriptoria és el pergamí, de bona qualitat i de forma quadrangular. Esta escrit amb lletra carolina molt clara, espaiada i plena de les abreujatures corrents en el moment de la seva redacció.

\section{LES TERRES DEL TERME DE MUR}

Les primeres notícies d'aquest terme situat a la Segarra, prop de Tarrega i de Vilagrassa, apareixen en un document del 27 de novembre de 1121, en el qual en Ramon Berenguer III dóna unes peces de terra a Gunter i a Guilia. Els límits de les mateixes ens donen uns llocs comuns als del nostre document: affrontat...de quinta in ipso reger qui discurrit de Cervaria, de tertia in stata qui exiit de Mauro et pergit ad pas de Vilagrassa, de quarta vero parte in terminum qui est inter Maurum et Tarrege (1). 
Durant el mes de febrer de 1178, trobant-se Alfons I a Santa Maria de Vallbona, va firmar una concordia amb els habitants de Mur, qui li juraren obediencia (2). Un any després, en el mes de gener de 1179, el mateix sobirà els atorgà protecció i defensa a canvi d'un cens anyal en especie, és a dir, 30 «migerias" de blat i 30 d'ordi.

Entre els signants d'aquest darrer document, veïns del Iloc, trobem al nostre Guillem Sabater (3).

El profesor Font i Rius escriu que, fins a 1181, aquest poblet de Mur fou una comunitat militar-agrària, amb una certa organització diferent a la de Tarrega (4).

Uns anys més tard, el novembre de 1192, Alfons I, va concedir el castell, el terme i les citades 60 «migerias» a Guillem d'Anglesola, a perpetuitat (5).

\section{EL LLOC DE MUR I SANTES CREUS}

Són moltes les notícies que, referides a Mur, apareixen en el «Llibre Blanch". Aqui sols assenyalarem les que tenen una relació més o menys directa amb el nostre text. Són les següents:

1. El 4 d'agost de 1181, Arnau de Cervera i la seva muller Agnes varen vendre al monestir diverses propietats a Cervera. Anglesola i Tarrega. El document té gran interés ja que una de les seves clàusules diu: et in Mor unum hominem nostrum Guillelmum Zabbater nomine, cum omnibus illis servitiis et usaticis que ipse nobis facet et facere solet vel debet et unos casales nostros, que sunt iuxta domus Guillelmi des Mor (6).

2. Un any després, aquest Guillem de Mur, donara a Santes Creus unes altres terres (7).

3. El 16 de novembre de 1185, Bernat de Santa Fe es dóna a si mateix junt amb unes terres del terme al monestir. En el límit d'aquesta propietat apareix un altre dels personatges del nostre document: a meridie in alaudio Guillelmi de Muntcortes (8).

4. En 1187, Sibilla, filla de Guillem de Santa Fe, germa de l'anterior, dóna als monjos unes altres terres (9).

5. El 13 de juliol de 1188, Berenguer de Muntcortés, fill del ja citat Guillem, ven a Santes Creus altres dues peces de terra (10).

6. El 13 de novembre de 1189 , el monestir i Arnau de Sorts cambien unes propietats per altres del citat terme (11).

7. En 1191, Ramon de Palmerona, la seva muller i el seu fill, donen els delmes que percebien de Mur al monestir (12), i

8. El 30 de juny de 1192, Arnau de Mur i la seva filla Beatriu, entregaren al monestir tots els delmes que cobraven en el lloc, excepte: hoc totum sicut dictum est, extra Guillelmi Zabbater retinuimus decimum et totum hoc qui nobis facere debet (13). 


\section{GUILLEM SABATER I LA DOCUMENTACIO COETANIA}

Guillem Sabater, fill, sembla de Arnau Sabater (14), apareix per primer cop en els documents de Santes Creus com a signatari de l'execució testamentaria d'en Ramon Sobirats, en 1177 (15). En 1179, el trobem entre els habitants del terme de Mur en el document reial citat (16), $i$ els anys $1181 \mathrm{i} 1192$ en els documents aportats en el paragraf anterior. El text que transcribim de 1197 ens diu que estava casat amb Maria, i que ven la seva propietat de Mur per 10 sous barcelonesos.

Dels altres personatges del document, a part de Guillem de Muntcortés, ja citat, i de l'escrivà Pere levita, que apareix com a testimoni en un cens atorgat al monestir per Pere de Torra i la seva muller Maria, el 2 de març de 1194 (17), no en tenim constància documental. 


\section{NOTAS}

(1) Llibre Blanc (edició Udina Martoreli), doc. 31.

(2) Liber Feudorum Maior (edició Miquel Rosell), doc. 167.

(3) Id., doc. 168

(4) J. FONT RIUS, Cartas de población y franquicia de Cataluña, Barcelona 1972, p. 696.

(5) Liber Feudorum, doc. 169.

(6) Llibre Blanch, doc. 241.

(7) Id., doc. 247.

(8) Id., doc. 279.

(9) Id., doc. 285.

(10) Id., doc. 310 .

(11) Id., doc. 329.

(12) Id., doc. 349

(13) Id., doc. 359.

(14) id., doc. 73.

(15) Id., doc. 133.

(16) Vid., nota 3.

(17) Libre Blanch, doc. 332 


\section{APENDIX DOCUMENTAL}

1197, agost, 12

Guillem Sabater i Maria, la seva muller, venen a l'abat Hug de Santes Creus, per 10 sous, unes terres al terme de Mur.

Arxiu Historic Nacional, Scala Dei, carpeta 2849, doc. 12.

Notum sit cunctis quod ego G(uillelmus) Cabater dez Mor et coniux mea Maria, nos insimul per/ nos et omnes nostros cum bona voluntante et sine vi, damus et diffinimus et solvemus ${ }^{3}$ domino Deo et Sancte Marie de Sanctis Crucibus, et vobis goni abbati (1), et fratribus eiusdem locii qui sunt presentes et futuri/ omnia nostra iura illius capconade terre quam tenebamus per G(uillelmum) de Muntcortes in/termino del Mor ante Vilagrassam et affrontat de I parte predicta capzo-/6nada in rivulo qui discurrit de Cervaria, de $\|^{\mathrm{a}}$ Ermensen de Brocha, de \|\|$^{\mathrm{a}} /$ in alaudio vestro, de $\mid I I^{a}$ Per(e) de Prinonosa.

De quanto hec affrontationes inclu-/dunt cum exiis et regressis earum, omnia nostra iura damus et diffinimus et solvemus omni/ ${ }^{9}$ tempore sine aliquo retentu quem ibi non facimus nos nec nostri et nullus homo vivens/ de isto die in antea per legem aliquam nec racionem valeat vobis obicere nec vestris/ fratribus que sunt et erunt inquietare, set imo de nostro iure in vestrum tradimus et damus $/{ }^{12}$ ad dandum, ad vendendum, ad impignorandum ad omnes vestras voluntates faciendas omni/ tempore et convenimus esse leiales et guarentes contra omnes personas. Et si quis hoc disrumpere/ voluerit in duplo vobis componat et in antea firmum stet omni tempore, et propter hoc donum/15 recepimus a vobis $X$ solidos barchinonenses/

Actum est hoc II idus augusti, anno Domini M.C.XC.VII. Sig (signe) num G. Cabater;/Sig (signe)num Marie, qui hanc cartam mandavimus scribi et firmavimus et firma- $/^{18}$ rique iussimus; Sig (signe)num Bertolomeu; Sig (signe) num B. Claver de Sanctis Crucibus/.

Petrus levita qui hoc, iussu G., scripsit, die et anno quo (signe notarial) supra, cum litteris supra/ positis in $1 \|^{\text {a }}$ linea.

(1) escrit damunt la ratlla: et vobis Ugoni abbati. 